\title{
Association between supportive attitude and adoptive practice of control strategy against COVID-19 amosng college students in China: a cross-sectional study
}

Dong Shen ${ }^{\dagger}$, Dan Liu ${ }^{\dagger}$, Miaochun Cai ${ }^{\dagger}$, Peiliang Chen, Zhenghe Wang, Yujie Zhang, Zhihao Li, Xiru Zhang, Xianbo Wu, Xingfen Yang ${ }^{*}$ and Chen Mao ${ }^{*}$ (i)

\begin{abstract}
Background: We investigated college students' attitude and compliance towards a prevention strategy involving use of non-pharmaceutical interventions (NPIs) against coronavirus disease 2019 (COVID-19).

Methods: We conducted a cross-sectional online survey in four universities in Guangdong Province (China) based on purposive sampling. A self-administered questionnaire was given to College students (CSs) to measure the supportive attitude towards an outbreak control strategy and adoption of NPIs in respondents.

Results: A total of 44,446 CSs participated between 31 January and 10 February 2020; 92.7\% of respondents supported the outbreak control strategy. The proportion of respondents who avoided public places, wore a facemask, avoid gatherings, and washed hands more frequently than usual was 94.8, 92.8, 91.2 and 86.9\%. respectively. A total of $76.5 \%$ respondents adopted all four measures. A supportive attitude was associated with NPI adoption. Students who were female, postgraduate, anxious, and not depressed tended to have a higher supportive attitude and higher chance of NPI adoption.
\end{abstract}

Conclusions: Higher supportiveness towards the disease control strategy for the Chinese public may lead to higher adoption rate of NPIs. Psychosocial factors were related to a supportive attitude and adoption of the NPI. We believe that our findings could aid policymakers to create NPIs to prevent and control emerging infectious diseases such as COVID-19.

Keywords: Coronavirus disease 19, College students, Prevention and control strategy, Attitude, Adoption

\section{Background}

Coronavirus disease 2019 (COVID-19) is caused by severe acute respiratory syndrome coronavirus-2 (SARSCoV-2) infection. COVID-19 was reported first in Wuhan (Hubei Province, China) in December 2019 [1]. The outbreak developed rapidly into a global pandemic.

\footnotetext{
*Correspondence: yangalice79@smu.edu.cn; maochen9@smu.edu.cn ${ }^{\dagger}$ Dong Shen, Dan Liu and Miaochun Cai contributed equally to this work. Department of Epidemiology, School of Public Health, Southern Medical University, Guangzhou 510515, China
}

Up to December 2020, 100,000 cases (including imported cases) had been reported in China. However, in some other countries where the first cases were reported in January 2020, such as the USA, Russia, the United Kingdom, and Kazakhstan, the number of cases has been increasing rapidly, reaching 19 million, 3.1 million, 2.4 million, and 200,000 by December 2020, respectively [2]. The difference in the scale of the epidemic in different countries maybe related to the difference in

C The Author(s). 2021 Open Access This article is licensed under a Creative Commons Attribution 4.0 International License, which permits use, sharing, adaptation, distribution and reproduction in any medium or format, as long as you give appropriate credit to the original author(s) and the source, provide a link to the Creative Commons licence, and indicate if changes were made. The images or other third party material in this article are included in the article's Creative Commons licence, unless indicated otherwise in a credit line to the material. If material is not included in the article's Creative Commons licence and your intended use is not permitted by statutory regulation or exceeds the permitted use, you will need to obtain permission directly from the copyright holder. To view a copy of this licence, visit http://creativecommons.org/licenses/by/4.0/ The Creative Commons Public Domain Dedication waiver (http://creativecommons.org/publicdomain/zero/1.0/) applies to the data made available in this article, unless otherwise stated in a credit line to the data. 
the attitude of the population to the disease and the measures implemented in those countries.

For emerging infectious diseases, due to a lack of efficacious antiviral agents or vaccine, non-pharmaceutical interventions (NPIs) are the most efficacious interventions to prevent and control their spread [3, 4]. During the epidemic of influenza A (H1N1) in 2009, NPIs helped to decrease transmission [5]. Community participation is particularly important for any NPI strategy to be successful [6-9]. Negative attitudes and practices by the public can impede successful campaigns against the spread of infectious diseases $[10,11]$.

At the early stage of the COVID-19 outbreak, the National Health Commission of China launched a control strategy containing several measures to prevent and control disease spread: free treatment to patients confirmed to have COVID-19; quarantine for people who were likely to have been exposed to SARS-CoV-2 (separation from the rest of the population); restrictions on travelling in and out of Wuhan City; closing down public entertainment facilities; extending the Spring Festival holidays; and delaying the return to school [12]. In addition to the strategy for the public, the Chinese government and its healthcare departments also gave recommendations and guidelines of NPIs for individuals to follow, such as use of a facemask and washing hands frequently. COVID-19 is an emerging infectious disease, so the public had little knowledge about it. NPI messages were propagated vigorously through television, mobiletelephone messages, social media (e.g., $\mathrm{WeChat}^{\mathrm{Tw}}$ ), the Internet, and newspapers to all community members.

Under these circumstances, the response and implementation by the public for a new NPI strategy are key elements for epidemic control. Additionally, timely feedback of this information is particularly important for health authorities to improve the overall control strategy.

College students (CSs) are important members of the community. They represent the younger, more receptive part of a population. We evaluated CSs' support and practice towards the NPI strategy against COVID-19 created by the Chinese government. The relationship between their support and practice in the initial period of the COVID-19 outbreak in China was also evaluated. Previous study has shown a gap between knowledge, attitudes, and behaviors toward some health-related events among people. For example, a study conducted among students in Cameroon showed that, although participants had good knowledge and a positive attitude towards infection by the human immunodeficiency virus, they did not undertake preventive practices [13]. Therefore, we intended to observe how consistent the attitude and behavior of CSs were in this public-health emergency.

\section{Methods}

\section{Ethical approval of the study protocol and consent to} participate

The protocol for information collection from participants was approved by the ethics committee of Southern Medical University (Guangzhou, China). This protocol was undertaken in accordance with the ethical standards noted in the 1964 Declaration of Helsinki and its later amendments. Participants were informed of the purpose and overview of the survey and had to provide written consent before completing the questionnaire.

\section{Study design}

From 31 January to 20 February 2020, we provided a cross-sectional online survey for CSs. A purposive sampling method was employed. We sorted universities in Guangdong into four categories according to their main area of specialty: medical, technology, economic, or comprehensive university. Then, we selected one university with $\geq 20,000$ students in each category as our sample. All the students in the universities were selected as participants of this study. The questionnaire used in our study was self-administered. The content and validity of the questionnaire was designed and assessed by six experienced reviewers: three epidemiologists, two specialists in social medicine, and one college counselor (Additional File 1). The questionnaire was sent through online communities at Southern Medical University and was collected via the website of the latter. The validity of the questionnaire was assessed by experts in public health and epidemiology. All questions had to be answered. The survey was anonymous and consent to participate was not required. The report of this study follows the STROBE statement.

\section{Measures and definitions}

The questionnaire consisted of sociodemographic characteristics, Knowledge, Attitude and Practices (KAP) questions, Center for Epidemiologic Studies Depression Scale (CES-D) for depression testing, and Self-Rating Anxiety Scale (SAS) for anxiety testing [14]. Cronbach's $\alpha$ was used to test the reliability of each part, which was $0.830,0.823$ and 0.856 for KAP, CES-D, and SAS respectively. The cutoff points of these scales were based on studies described previously [15-17]. All participants were required to answer if they had any chance of being exposed to SARS-CoV-2.

In the questionnaire, we defined a supportive attitude towards control of the outbreak by asking "Do you agree with the country's prevention and disease control policies?", which include isolation of close contact, largescale nucleic-acid testing, and promotion of NPIs. Accordingly, the respondents stated "agree" or "disagree". Adoption of NPI measures included washing 
hands frequently, using a facemask following recommendations, avoidance of gatherings, and avoidance of public places. Participants were required to answer "complied" or "not complied" to each question. In addition, we defined respondents who adopted all four interventions as "high compliance" and those who did not as "not high compliance". The outbreak-control strategy and selfprotection guidelines were announced on 25 January 2020. Before investigation, we confirmed that participants were aware of the content of the NPI strategy.

We ascertained if participants had a history of potential exposure to SARS-CoV-2 by asking three questions. That is, whether: (i) they travelled to or through Wuhan in the previous 2 weeks; (ii) their family members had been diagnosed with COVID-19 or quarantined; (iii) their family members had travelled to or through Wuhan in the previous 2 weeks. If the answer to all of these questions was negative, the respondents were defined as having "no exposure history".

\section{Data analyses}

All data collected were cross-checked and imported into Excel $^{\text {tw }}$ (Microsoft, Redmond, WA, USA) in simplified Chinese, coded and translated into English, and analyzed using R 3.6.0 (R Foundation for Statistical Computing, Vienna, Austria). The basic characteristics of respondents were first presented as a number (percentage) for categorical variables.

Then, the difference in a supportive attitude to the COVID-19 control strategy and the difference in prevalence of adoption of this strategy in different subgroups was presented. The absolute risk reduction (ARR), number need to treat (NNT) and their 95\% confidence intervals (CIs) were calculated. ARR was the difference of event proportion between two groups, and its $95 \% \mathrm{CI}$ was computed based on Wilson procedure with a correction for continuity. NNT was the reciprocal of the absolute risk difference (1/ARR), and its $95 \% \mathrm{CI}$ was obtained by taking reciprocals of the values defining the CI for ARR.

The association between a supportive attitude towards the COVID-19 control strategy and its adoption was examined. The significance of differences was assessed by the $\chi^{2}$ test for categorical variables and $\mathrm{z}$-ratio for independent proportions. Multivariable logistic regression was carried out to test the association between a supportive attitude towards the NPI strategy and adoption of its measures. Multi-collinearity was ruled out for all covariates based on the collinearity test. Covariates (age, sex, degree course (undergraduate or postgraduate), primary degree (medicine or non-medicine), anxiety score, and depression score were adjusted. Matching of the propensity score based on logistic regression was undertaken to minimize the potential bias in all subgroups, and age, sex, degree course, primary degree, anxiety score, depression score and history of exposure were adjusted accordingly. $P<0.05$ was considered significant. Missing data were tested by margin plots and considered to be "missing at random". All missing data were excluded during each analysis.

\section{Results}

\section{Characteristics of respondents}

From 44,451 respondents, 44,446 questionnaires were eligible, the response rate was $54.1 \%$ and the median filling time was $664 \mathrm{~s}\left(\mathrm{P}_{25}-\mathrm{P}_{75}, 523-868\right)$. The mean age of all respondents was $21 \pm 2.1$ (interquartile range, 19-22) years. Overall, $54.5 \%$ of respondents were female, $89.4 \%$ were undergraduate, and $29.5 \%$ were medical students. Among all respondents, 2138 students had a history of exposure to SARS-CoV-2. Among all students who completed the SAS or CESD questions, $0.6 \%$ showed signs of anxiety (score $\geq 50$ ), and $33.1 \%$ of students showed signs of depression (score $\geq 16$ ) (Table 1).

The measures adopted most keenly were avoidance of public places (94.8\%), followed by use of a facemask (92.8\%), avoidance of gatherings $(91.2 \%)$ and washing hands frequently $(86.9 \%)$. Of all respondents, $76.5 \%$ reported that they would use all four measures for protection against COVID-19 (Table 1).

\section{Supportive attitude towards the non-pharmaceutical intervention strategy in different subgroups}

Female and postgraduate students showed a slightly higher percentage of a supportive attitude towards the NPI strategy against COVID-19 compared with that from male and undergraduate students (ARR of 2.0 , and $1.8 \%$, respectively). Respondents with no sign of depression had a more supportive attitude towards strategies than those who were depressed $(94.2 \%$ vs. $90.5 \%, A R R=3.7 \%)$. However, respondents who felt anxious were much more approving towards the NPI strategy (95.8\% of respondents) than those who did not feel anxious (23.3\%). Those who had been exposed to SARS-CoV-2 tended to have less of a supportive attitude than those who had no exposure history $(95.8 \%$ vs. $91.5 \%$, ARR $=4.3 \%)$.

We compared the adjusted number needed to treat (NNT) in subgroups. The smallest value of NNT was 4 and was found in the anxiety group, which suggested that anxiety was the most important factor influencing the supportive attitude of respondents. The second most important factor was exposure history $(\mathrm{NNT}=23)$ (Table 2).

\section{Adoption of non-pharmaceutical intervention measures in different subgroups}

The measure adopted by most respondents was avoidance of public places (94.8\%), followed by use of a 
Table 1 Characteristics of college students in the study, $n=44,446$

\begin{tabular}{|c|c|}
\hline Characteristic & Number (\%) \\
\hline Age, mean $\pm S D$, years & $21 \pm 2.4$ \\
\hline Female & $24,231(54.5)$ \\
\hline \multicolumn{2}{|l|}{ Grade } \\
\hline Undergraduate & $39,723(89.4)$ \\
\hline Postgraduate & $4723(10.6)$ \\
\hline \multicolumn{2}{|l|}{ Primary degree } \\
\hline Medicine & $13,116(29.5)$ \\
\hline Other & $31,330(70.5)$ \\
\hline \multicolumn{2}{|c|}{ History of exposure to COVID-19 } \\
\hline Yes & $2138(4.8)$ \\
\hline No & $42,308(95.2)$ \\
\hline \multicolumn{2}{|l|}{ Anxiety score } \\
\hline$<50$ & $44,207(99.4)$ \\
\hline$\geq 50$ & $239(0.6)$ \\
\hline \multicolumn{2}{|l|}{ Depression score } \\
\hline$<16$ & $29,756(66.9)$ \\
\hline$\geq 16$ & $14,690(33.1)$ \\
\hline \multicolumn{2}{|c|}{ Attitude to the strategy to control the epidemic } \\
\hline Supportive & $30,040(92.8)$ \\
\hline Not supportive & $2340(7.2)$ \\
\hline \multicolumn{2}{|c|}{ Using a facemask in accordance with the NPI } \\
\hline Complied & $41,264(92.8)$ \\
\hline Not complied & $3183(7.2)$ \\
\hline \multicolumn{2}{|c|}{ Washing hands frequently } \\
\hline Complied & $38,613(86.9)$ \\
\hline Not complied & $5833(13.1)$ \\
\hline \multicolumn{2}{|c|}{ Avoidance of public places } \\
\hline Complied & $42,134(94.8)$ \\
\hline Not complied & $2312(5.2)$ \\
\hline \multicolumn{2}{|l|}{ Avoidance of gatherings } \\
\hline Complied & $40,544(91.2)$ \\
\hline Not complied & $3902(8.8)$ \\
\hline \multicolumn{2}{|l|}{ Applied all measures } \\
\hline Yes & $34,005(76.5)$ \\
\hline No & $10,041(23.5)$ \\
\hline
\end{tabular}

Note. Data are number (\%) unless stated otherwise

facemask (92.8\%), avoidance of gatherings $(91.2 \%)$ and hand washing frequently $(86.9 \%)$ (Table 2 ). Being female, having a high level of education, not suffering from depression, being anxious, and having a history of exposure positively influenced adoption of NPI measures (Table 4). The most important influencing factor was anxiety $(\mathrm{ARR}=28 \%, \mathrm{NNT}=4)$, followed by depression $(9.7 \%$ $10)$, sex $(5.9 \%, 17)$ and level of education $(4.5 \%, 22)$; exposure history had only a small influence $(2.9 \%, 34)$ (Table 3).

Associations between a supportive attitude towards the non-pharmaceutical intervention strategy and adoption of its measures

There were significant associations between approval attitude of the NPI strategy and compliance with all of its measures. People who disagreed with the control strategy had a negative association with wearing a facemask (odds ratio, 1.55; 95\%CI 1.42 to 1.68 ), washing hands frequently $(1.57 ; 1.47$ to 1.67$)$, avoidance of gatherings (1.26; 1.17 to 1.36$)$, avoidance of public places $(1.48 ; 1.34$ to 1.62$)$ and adoption of all measures $(1.33 ; 1.26$ to 1.39$)$ (Table 4).

\section{Discussion}

We found that $92.7 \%$ of respondents had a supportive attitude towards the NPI strategy for control of COVID19. The survey was completed during the winter vacation in China. All CSs were at home for the holidays, and they had the same access to information as the general population. A high prevalence of support indicates that the NPI strategy had been well publicized. About $5.5 \%$ of respondents reported that they disagreed with the NPI strategy. Compared with respondents who agreed with the NPI strategy, the respondents who disagreed tended to be male, have a low level of education, and to suffer from depression. Studies have shown consistently that men express a lower level of concern towards health risks $[18,19]$. This may be the reason why men had a lower supportive attitude than that of women in our study. Postgraduate students had a slightly higher supportive attitude about the NPI strategy than that of undergraduate students. Studies on Middle East respiratory syndrome (MERS)-related knowledge, preventive behaviors, and risk perception among nursing students during the MERS outbreak showed that senior nursing students and female students had a supportive attitude and practice of measures to control MERS [20-22]. These studies suggest that intelligence has a positive effect on the attitude towards a health strategy.

Importantly, the psychological status of respondents was linked to a supportive attitude of the NPI strategy. Depression was a negative influencing factor in the supportive attitude of the NPI strategy, whereas anxiety had a positive influence regardless of sex or level of education. This result may have been because people suffering from depression frequently lack interest in life [23]. The reasons why anxiety was related to a supportive attitude to the NPI strategy may have been because COVID-19 caused anxiety in these respondents. Few studies have focused on anxiety and attitude towards intervention measures to control and prevent disease. This suggests 
Table 2 Supportive attitude towards a non-pharmaceutical intervention strategy to control COVID-19 among respondents by subgroups

\begin{tabular}{|c|c|c|c|c|}
\hline Subgroup & Percentage of supportiveness & ARR $(95 \% \mathrm{Cl})$ & P of ARR & NNT $(95 \% \mathrm{Cl})$ \\
\hline \multicolumn{5}{|l|}{ Sex } \\
\hline Male vs. female & $91.8 \%$ vs. $93.8 \%$ & $2.0 \%(1.4-2.6 \%)$ & $<0.001$ & $50(38-71)$ \\
\hline Adjusted $\boldsymbol{\dagger}$ & $91.8 \%$ vs. $93.8 \%$ & $2.0 \%(1.4-2.6 \%)$ & $<0.001$ & $50(38-71)$ \\
\hline \multicolumn{5}{|l|}{ Degree course } \\
\hline Undergraduate vs. postgraduate & $92.4 \%$ vs. $95.2 \%$ & $2.8 \%(2.1-3.5 \%)$ & $<0.001$ & $35(29-48)$ \\
\hline Adjusted $\boldsymbol{t}$ & $93.4 \%$ vs. $95.2 \%$ & $1.8 \%(0.5-3.0 \%)$ & 0.003 & $57(33-200)$ \\
\hline \multicolumn{5}{|l|}{ Primary degree } \\
\hline Medicine vs. other & $93.2 \%$ vs. $92.5 \%$ & $0.6 \%(0.1-1.2 \%)$ & 0.029 & $157(83-1000)$ \\
\hline Adjusted $\mathbf{t}$ & $92.7 \%$ vs. $92.5 \%$ & $0.2 \%(-0.4$ to $0.8 \%)$ & 0.55 & $540(-250$ to 125$)$ \\
\hline \multicolumn{5}{|l|}{ Depression score } \\
\hline$<16$ vs. $\geq 16$ & $93.8 \%$ vs. $90.5 \%$ & $3.3 \%(2.6-3.9 \%)$ & $<0.001$ & $30(26-38)$ \\
\hline Adjusted $\mathbf{t}$ & $94.2 \%$ vs. $90.5 \%$ & $3.7 \%(3.0-4.4 \%)$ & 0.002 & $27(23-33)$ \\
\hline \multicolumn{5}{|l|}{ Anxiety score } \\
\hline$<50$ vs. $\geq 50$ & $92.9 \%$ vs. $72.5 \%$ & $20.4 \%(14.2-26.6 \%)$ & $<0.001$ & $5(4-7)$ \\
\hline Adjusted $\boldsymbol{\dagger}$ & $95.8 \%$ vs. $72.5 \%$ & $23.3 \%(16.6-30.0 \%)$ & $<0.001$ & $4(3-6)$ \\
\hline \multicolumn{5}{|l|}{ Exposure history } \\
\hline No vs. Yes & $92.9 \%$ vs. $91.5 \%$ & $1.4 \%(0.1-2.7 \%)$ & 0.026 & $73(37-1000)$ \\
\hline Adjusted $\boldsymbol{t}$ & $95.8 \%$ vs. $91.5 \%$ & $4.3 \%(2.8-5.8 \%)$ & $<0.001$ & $23(17-36)$ \\
\hline
\end{tabular}

Note: Percentage of supportiveness refers to the proportion of respondents who had a supportive attitude to the NPI strategy to control the spread of COVID-19. ARR, absolute risk reduction. NNT, number needed to treat. P (two-tailed) was based on the z-ratio test. tcase was adjusted by matching of the propensity score based on age, sex, degree course, primary degree, depression score, anxiety score, or exposure history

Table 3 Adoption of the non-pharmaceutical intervention strategy to control COVID-19 among respondents by subgroups

\begin{tabular}{|c|c|c|c|c|}
\hline Subgroup & Percentage of adoption & ARR $(95 \% \mathrm{Cl})$ & P of ARR & NNT $(95 \% \mathrm{Cl})$ \\
\hline \multicolumn{5}{|l|}{ Sex } \\
\hline Male vs. female & $73.4 \%$ vs. $79.1 \%$ & $5.7 \%(4.9-6.5 \%)$ & $<0.001$ & $18(15-20)$ \\
\hline Adjusted $\boldsymbol{\dagger}$ & $73.3 \%$ vs. $79.2 \%$ & $5.9 \%(4.9-6.8 \%)$ & $<0.001$ & $17(15-20)$ \\
\hline \multicolumn{5}{|l|}{ Degree course } \\
\hline Undergraduate vs. postgraduate & $75.3 \%$ vs. $81.6 \%$ & $6.3 \%(5.0-7.5 \%)$ & $<0.001$ & $16(13-20)$ \\
\hline Adjusted $\mathbf{t}$ & $77.1 \%$ vs. $81.6 \%$ & $4.5 \%(2.4-6.6 \%)$ & $<0.001$ & $22(15-42)$ \\
\hline \multicolumn{5}{|l|}{ Primary degree } \\
\hline Medicine vs. other & $76.3 \%$ vs. $76.7 \%$ & $0.4 \%(-0.5$ to $1.2 \%)$ & 0.408 & 250 ( -200 to 83$)$ \\
\hline Adjusted $\boldsymbol{\dagger}$ & $74.9 \%$ vs. $76.7 \%$ & $1.7 \%(0.8-2.7 \%)$ & $<0.001$ & $59(37-125)$ \\
\hline \multicolumn{5}{|l|}{ Depression score } \\
\hline$<16$ vs. $\geq 16$ & $79.7 \%$ vs. $70.0 \%$ & $9.7 \%(8.8-10.5 \%)$ & $<0.001$ & $10(10-11)$ \\
\hline Adjusted $\boldsymbol{\dagger}$ & $79.7 \%$ vs. $70.0 \%$ & $9.7 \%(8.7-10.7 \%)$ & $<0.001$ & $10(9-11)$ \\
\hline \multicolumn{5}{|l|}{ Anxiety score } \\
\hline$<50$ vs. $\geq 50$ & $76.7 \%$ vs. $48.5 \%$ & $28.1 \%(21.8-34.5 \%)$ & $<0.001$ & $4(3-5)$ \\
\hline Adjusted $\boldsymbol{\dagger}$ & $76.6 \%$ vs. $48.5 \%$ & $28.0 \%(19.7-36.3 \%)$ & $<0.001$ & $4(3-5)$ \\
\hline \multicolumn{5}{|l|}{ Exposure } \\
\hline No vs. yes & $76.8 \%$ vs. $71.3 \%$ & $5.5 \%(3.5-7.5 \%)$ & $<0.001$ & $18(29-13)$ \\
\hline Adjusted $\boldsymbol{\dagger}$ & $74.2 \%$ vs. $71.3 \%$ & $2.9 \%(0.2-5.6 \%)$ & $<0.001$ & $34(500-18)$ \\
\hline
\end{tabular}

Note: Percentage of adoption refers to the percentage of respondents who undertook all four measures (hand hygiene, use of a facemask, avoidance of gatherings, and avoidance of public places). ARR, absolute risk reduction. NNT, number needed to treat. P (two-tailed) was based on the z-ratio test. †case was adjusted by matching of the propensity score based on age, sex, degree course, primary degree, depression score, anxiety score, or exposure history 
Table 4 Association between a supportive attitude and adoption of control measures for COVID-19 among respondents (OR, 95\%Cl)

\begin{tabular}{|c|c|c|c|c|c|}
\hline Factor & $\begin{array}{l}\text { Using a } \\
\text { facemask }\end{array}$ & $\begin{array}{l}\text { Washing hands } \\
\text { frequently }\end{array}$ & $\begin{array}{l}\text { Avoidance of } \\
\text { gatherings }\end{array}$ & $\begin{array}{l}\text { Avoidance of public } \\
\text { places }\end{array}$ & $\begin{array}{l}\text { Adoption of all } \\
\text { measures }\end{array}$ \\
\hline Supportive & 1.00 (reference) & & & & \\
\hline Not supportive & $1.55(1.42-1.68)$ & $1.57(1.47-1.67)$ & $1.26(1.17-1.36)$ & $1.48(1.34-1.62)$ & $1.33(1.26-1.39)$ \\
\hline Age $<21$ years & 1.00 (reference) & & & & \\
\hline Age $>21$ years & $1.14(1.06-1.23)$ & $1.02(0.96-1.08)$ & $0.81(0.75-0.87)$ & $0.92(0.84-1.01)$ & $0.93(0.89-0.98)$ \\
\hline Male sex & 1.00 (reference) & & & & \\
\hline Female Sex & $0.52(0.49-0.57)$ & $0.74(0.71-0.79)$ & $0.54(0.51-0.58)$ & $0.42(0.38-0.46)$ & $0.67(0.64-0.70)$ \\
\hline Undergraduate & 1.00 (reference) & & & & \\
\hline Postgraduate & $0.72(0.66-0.81)$ & $0.62(0.57-0.66)$ & $0.84(0.77-0.92)$ & $0.97(0.87-1.09)$ & $0.72(0.68-0.76)$ \\
\hline Medicine & 1.00 (reference) & & & & \\
\hline Others & $0.59(0.51-0.69)$ & $0.68(0.61-0.76)$ & $0.71(0.61-0.81)$ & $0.63(0.52-0.76)$ & $0.67(0.613-0.73)$ \\
\hline Depression score $<16$ & 1.00 (reference) & & & & \\
\hline Depression score $>16$ & $3.09(2.31-4.12)$ & $2.42(1.839-3.17)$ & $3.75(2.832-4.94)$ & $4.75(3.501-6.38)$ & $2.37(1.831-3.07)$ \\
\hline Anxiety score $<50$ & 1.00(reference) & & & & \\
\hline Anxiety score < 50 & $1.89(1.75-2.03)$ & $1.77(1.67-1.87)$ & $1.45(1.35-1.55)$ & $1.39(1.27-1.51)$ & $1.68(1.61-1.75)$ \\
\hline
\end{tabular}

Note: Odds ratio ( $95 \%$ confidence interval) was adjusted by age, sex, level of education, primary degree, level of depression, and level of anxiety

that people who have moderate anxiety caused by public-health emergencies can enhance their implementation of relevant control strategies.

The measure adopted by most respondents was avoidance of public places (94.8\%), followed by use of a facemask (92.8\%), avoidance of gatherings (91.2\%) and washing hands frequently (86.9\%). Compared with the other three measures, the prevalence of adoption of handwashing was relatively low. Implementation of this measure is related to sanitation facilities: in China, there are not enough facilities for outdoor handwashing. The inconvenience and difficulty of maintaining a NPI measure is a potential obstacle to its adoption. During the epidemic of influenza A (H1N1) in 2009, CSs and the general population had a low acceptance of NPI measures because they disrupted workplace and leisure activities $[24,25]$.

We found that $76.5 \%$ of respondents adopted all four NPI measures. Zottarelli and colleagues showed that in the influenza A (H1N1) epidemic in 2009, when evaluating CSs in the USA, $72.1 \%$ of the study cohort reported frequent handwashing, yet only $10.7 \%$ avoided public gatherings [26]. In another study conducted in a public university in the USA, the proportion of students who took any selfprotective measure against influenza A (H1N1) was 64.9\% [24]. Those results indicate that more CSs in China implement NPI measures than CSs in the USA.

There was a positive correlation between supportive attitude and adoption behaviors towards the NPI strategy during the COVID-19 epidemic (Table 4). People with a supportive attitude towards the NPI strategy indicated that they had a supportive attitude of protection against and risk of COVID-19, so it is likely that they would be willing to adopt the measures. A study by Wang and colleagues on the factors that determine adoption of preventive behaviors during the influenza A (H7N9) epidemic revealed that a protective attitude positively influenced an individual's willingness to take recommended actions [27].

Being female, having a high level of education, and being anxious meant that you were likely to adopt the measures of the NPI strategy. Importantly, respondents who reported having anxiety had a $28 \%$ higher chance of adopting the measures than those who were not suffering from anxiety. This finding suggested that the anxiety in CSs may have been caused by COVID-19. These results echo those from a study on perceived risk, anxiety, and behavioral responses in the early phase of the influenza A (H1N1) epidemic in the Netherlands [11]. Depression may negatively influence adoption of NPI measures, which may be because depression made people less willing to take action and be more indifferent about safety.

Medical knowledge did not influence adoption of measures. Interestingly, respondents who did not have an exposure history to COVID-19 patients or epidemic areas had less of a supportive attitude and adoptive behaviors to the measures compared with those who had an exposure history (Tables 3 and 4). This finding may have been due to two reasons. First, if respondents had been exposed but did not develop COVID-19, their risk perception will be reduced, which is also known as "optimism bias". Parry and colleagues showed that, compared with people who had food poisoning due to Salmonella species, people who had not experienced food poisoning due to Salmonella species perceived their personal risk 
from food poisoning to be lower [28]. Second, it may be that our respondents had reduced anxiety about COVID19; Bults and colleagues showed that anxiety decreased over time in the influenza A (H1N1) epidemic in 2009 [11].

Our study had two main limitations, as a crosssectional study it may be weak in terms of causation, and there may have been an information bias because the study data were time-sensitive and self-reported. However, our study had three main advantages. First, this survey was done shortly after the COVID-19 outbreak, which might indicate how the respondents would actually react. Second, we analyzed the impact on a supportive attitude and adoptive action towards the NPI strategy by the social demographics and psychological status of CSs, which has been studied scarcely previously. Third, this is the first study focusing on a COVID-19-related supportive attitude and adoption towards an NPI strategy. These results can provide: (i) insights for public-health decision-makers; (ii) helpful information on the NPI measures people are willing to adopt (and the factors affecting adoption) during an emerging epidemic.

\section{Conclusions}

Our results suggest that supportiveness towards the disease control strategy for the Chinese public may lead to higher adoption rate of NPIs for individuals, including more challenging measures such as social distancing. It also suggested that policymakers should pay more attention to people suffering from anxiety and depression, who might be less likely to support the policy or prevention measures. Further research is needed to understand differences in responses from other populations, what might affect a supportive attitude, and how these findings will affect action in future outbreaks of infectious diseases.

\section{Abbreviations}

ARR: Absolute risk reduction; CES-D: Center for Epidemiologic Studies Depression Scale; COVID-19: Coronavirus disease 2019; CSs: College students; MERS: East respiratory syndrome; NPIs: Non-pharmaceutical interventions; NNT: Number needed to treat; OR: Odds ratio; SAS: Self-Rating Anxiety Scale; SARS-CoV-2: Severe acute respiratory syndrome coronavirus-2; 95\%Cl: 95\% confidence interval

\section{Supplementary Information}

The online version contains supplementary material available at https://doi. org/10.1186/s12889-021-10752-6

Additional file 1. Questionnaire investigating KAP on COVID-19 and mental health for college students.

\section{Acknowledgements}

We thank Zhihai Lin, Duo Zhang, Yun Mo and other team members at SMU for assistance in administering the online surveys. We thank Qing Chen for research support.

\section{Authors' contributions}

$\mathrm{CM}$ is the principal investigator of the study and obtained the necessary funds. Together with DS and DL, MC designed the study and wrote the study protocol. CM and DS contributed to the conception of the study. PC, $\mathrm{ZL}$, and ZW contributed significantly to analyses and manuscript preparation. $D S, D L$, and $M C$ undertook the data analyses and wrote the manuscript. $Y Z$ and $X Z$ helped undertake analyses with constructive discussions. XW, CM and $\mathrm{XY}$ provided resources and designed all laboratory methods. All authors approved the version of the manuscript shown here.

\section{Funding}

This study was funded and supported by the Zhejiang University Special Scientific Research Fund for COVID-19 prevention and control (K920330111). The Funding aims to promote prevention of COVID-19, related public-health studies, and basic medical research. However, Zhejiang University had no role in the design, analysis, or writing of this article

\section{Availability of data and materials}

The authors declare that the data supporting the findings of this study will be shared upon reasonable request to the corresponding author.

\section{Declarations}

\section{Ethics approval and consent to participate}

The protocol for collection of information from participants was approved by the ethics committee of Southern Medical University (Guangzhou, China). This protocol was undertaken in accordance with the ethical standards noted in the 1964 Declaration of Helsinki and its later amendments. Participants provided written informed consent before completing the online questionnaire.

\section{Consent for publication}

Not applicable.

\section{Competing interests}

The authors declare that they have no competing interests.

Received: 7 August 2020 Accepted: 4 April 2021

Published online: 26 April 2021

\section{References}

1. Zhao D, Yao F, Wang L, Zheng L, Gao Y, Ye J, et al. A comparative study on the clinical features of Coronavirus 2019 (COVID-19) pneumonia with other pneumonias. Clin Infect Dis. 2020;71:756-61.

2. Coronavirus Disease (COVID-19) Situation Reports. 2021-04-23T08:28:03.000Z https://www.who.int/emergencies/diseases/novel-coronavirus-2019/situa tion-reports. Accessed 23 Apr 2021.452Z.

3. Cowling BJ, Aiello AE. Public health measures to slow community spread of Coronavirus Disease 2019. J Infect Dis. 2020;221:1749-51.

4. Eccleston-Turner M, Phelan A, Katz R. Preparing for the next pandemic - the WHO's global influenza strategy. N Engl J Med. 2019;381(23):2192-4. https:// doi.org/10.1056/NEJMp1905224

5. Fong MW, Gao H, Wong JY, Xiao J, Shiu EYC, Ryu S, Cowling BJ. Nonpharmaceutical Measures for Pandemic Influenza in Nonhealthcare Settings-Social Distancing Measures. Emerg Infect Dis. 2020;26:976-84.

6. Herbert M, Riyaz BS, Thangaraj S. Community perception regarding rabies prevention and stray dog control in urban slums in India. J Infect Public Health. 2012;5(6):374-80. https://doi.org/10.1016/j.jiph.2012.05.002

7. Cowling BJ, Ng DM, Ip DK, Liao Q, Lam WW, Wu JT, et al. Community psychological and behavioral responses through the first wave of the 2009 influenza a(H1N1) pandemic in Hong Kong. J Infect Dis. 2010;202(6):867-76. https://doi.org/10.1086/655811

8. Krogstad DJ, Ruebush TN. Community participation in the control of tropical diseases. Acta Trop. 1996;61(2):77-8. https://doi.org/10.1016/0001706X(96)00009-5

9. Bermejo A, Bekui A. Community participation in disease control. Soc Sc Med. 1993;36(9):1145-50. https://doi.org/10.1016/0277-9536(93)90234-U

10. Bults M, Beaujean DJ, Richardus JH, Voeten HA. Perceptions and behavioral responses of the general public during the 2009 influenza a (H1N1) pandemic: a systematic review. Disaster Med Public Health Prep. 2015;9(2): 207-19. https://doi.org/10.1017/dmp.2014.160 
11. Bults M, Beaujean DJ, de Zwart O, Kok G, van Empelen P, van Steenbergen $J E$, et al. Perceived risk, anxiety, and behavioural responses of the general public during the early phase of the influenza a (H1N1) pandemic in the Netherlands: results of three consecutive online surveys. BMC Public Health. 2011;11(1):2. https://doi.org/10.1186/1471-2458-11-2 .

12. Bureau ODPC: Compilation of public prevention guidelines for pneumonia prevention and control of new coronavirus infection; 2020.

13. Nubed CK, Akoachere J-FTK. Knowledge, attitudes and practices regarding HIV/AIDS among senior secondary school students in Fako Division, South West Region, Cameroon. BMC Public Health. 2016;16:847.

14. Wang Z, Yang H, Yang Y, Liu D, Li Z, Zhang X, et al. Prevalence of anxiety and depression symptom, and the demands for psychological knowledge and interventions in college students during COVID-19 epidemic: a large cross-sectional study. J AFFECT DISORDERS. 2020;275:188-93. https://doi. org/10.1016/j.jad.2020.06.034

15. Dunstan DA, Scott N. Norms for Zung's self-rating anxiety scale. BMC PSYC HIATRY. 2020;20(1):90. https://doi.org/10.1186/s12888-019-2427-6 .

16. Jiang L, Wang Y, Zhang Y, Li R, Wu H, Li C, et al. The Reliability and Validity of the Center for Epidemiologic Studies Depression Scale (CES-D) for Chinese University Students. FRONT PSYCHIATRY. 2019;10:315. https://doi. org/10.3389/fpsyt.2019.00315.

17. Stahl D, Sum CF, Lum SS, Liow PH, Chan YH, Verma S, et al. Screening for depressive symptoms: validation of the center for epidemiologic studies depression scale (CES-D) in a multiethnic group of patients with diabetes in Singapore. Diabetes Care. 2008;31(6):1118-9. https://doi.org/10.2337/dc07-2019 .

18. Morioka R. Gender difference in the health risk perception of radiation from Fukushima in Japan: the role of hegemonic masculinity. Soc Sci Med. 2014; 107:105-12. https://doi.org/10.1016/.jsocscimed.2014.02.014

19. Byrnes J, Miller D, Schafer W. Gender differences in risk taking: a metaanalysis. Psychol Bull. 1999;125(3):367-83. https://doi.org/10.1037/0033-2 909.125.3.367

20. Zhang Y, Xia T, Huang L, Yin M, Sun M, Huang J, et al. Factors influencing user engagement of health information disseminated by Chinese provincial Centers for Disease Control and Prevention on WeChat: observational study. JMIR MHEALTH UHEALTH. 2019;7(6):e12245. https://doi.org/10.2196/12245.

21. Kim JS, Choi JS. Middle East respiratory syndrome-related knowledge, preventive behaviours and risk perception among nursing students during outbreak. J Clin Nurs. 2016;25(17-18):2542-9. https://doi.org/10.1111/ jocn.13295

22. Choi JS, Kim JS. Factors influencing preventive behavior against Middle East respiratory syndrome-coronavirus among nursing students in South Korea. Nurse Educ Today. 2016;40:168-72. https://doi.org/10.1016/..nedt.2016.03.006

23. Rosenstrom T, Jokela M. Reconsidering the definition of major depression based on collaborative psychiatric epidemiology surveys. J Affect Disord. 2017;207:38-46. https://doi.org/10.1016/j.jad.2016.09.014

24. Mitchell T, Dee DL, Phares CR, Lipman HB, Gould LH, Kutty P, et al. Nonpharmaceutical interventions during an outbreak of 2009 pandemic influenza a (H1N1) virus infection at a large public university, Apri--may 2009. Clin Infect Dis. 2011;52(Suppl 1):S138-45. https://doi.org/10.1093/cid/ciq056 .

25. Stebbins S, Downs JS, Vukotich CJ. Using nonpharmaceutical interventions to prevent influenza transmission in elementary school children: parent and teacher perspectives. J Public Health Manag Pract. 2009;15(2):112-7. https:// doi.org/10.1097/01.PHH.0000346007.66898.67

26. Zottarelli LK, Sunil TS, Flott P, Karbhari S. College student adoption of nonpharmaceutical interventions during the 2009 H1N1 influenza pandemic: a study of two Texas universities in fall 2009. Prev Med. 2012;55(5):497-9. https://doi.org/10.1016/j.ypmed.2012.08.009

27. Wang FP, Wei JP, Shi X. Compliance with recommended protective actions during an H7N9 emergency: a risk perception perspective. DISASTERS. 2018; 42(2):207-32. https://doi.org/10.1111/disa.12240 .

28. Parry SM, Miles S, Tridente A, Palmer SR. Differences in perception of risk between people who have and have not experienced Salmonella food poisoning. Risk Anal. 2004;24(1):289-99. https://doi.org/10.1111/j.0272-4332.2 004.00429.x .

\section{Publisher's Note}

Springer Nature remains neutral with regard to jurisdictional claims in published maps and institutional affiliations.

Ready to submit your research? Choose BMC and benefit from:

- fast, convenient online submission

- thorough peer review by experienced researchers in your field

- rapid publication on acceptance

- support for research data, including large and complex data types

- gold Open Access which fosters wider collaboration and increased citations

- maximum visibility for your research: over $100 \mathrm{M}$ website views per year

At BMC, research is always in progress.

Learn more biomedcentral.com/submissions 